\title{
Nonsingular Fast Terminal Sliding Mode Control with Extended State Observer and Disturbance Compensation for Position Tracking of Electric Cylinder
}

\author{
Duoyang $\operatorname{Li} \mathbb{D}^{1,2}$ and Junzheng Wang ${ }^{1,2}$ \\ ${ }^{1}$ Key Laboratory of Intelligent Control and Decision of Complex Systems, Beijing 100081, China \\ ${ }^{2}$ School of Automation, Beijing Institute of Technology, Beijing 100081, China \\ Correspondence should be addressed to Duoyang Li; ldy_ll@sina.com
}

Received 12 March 2018; Accepted 3 May 2018; Published 26 June 2018

Academic Editor: Luis Gracia

Copyright (C) 2018 Duoyang Li and Junzheng Wang. This is an open access article distributed under the Creative Commons Attribution License, which permits unrestricted use, distribution, and reproduction in any medium, provided the original work is properly cited.

\begin{abstract}
The position tracking problem of the electric cylinder, which has internal perturbation, external disturbance, and measurement noise of the output, is studied in this paper. A control method is proposed for achieving high tracking accuracy and tracking velocity for the wheel-legged robot application. Nonsingular fast terminal sliding mode (NFTSM) control is investigated to ensure that the system output can track the reference input in finite time. Besides, extended state observer (ESO) of the active disturbance rejection control (ADRC) is used to estimate the system lumped perturbation and compensated it in the controller based on the terminal sliding mode. This greatly reduces the chattering of the system caused by the gain of the sliding mode switch. Furthermore, tracking differentiator is designed to attenuate the output measurement noise. Simulation and experimental results illustrate that the NFTSM with ESO and TD algorithm, which is presented in this paper, has obvious superiority in the tracking precision and the antijam ability.
\end{abstract}

\section{Introduction}

Since Boston Dynamics successfully developed the BigDog, the world set off a wave of robotics research and the driving mode has gradually shifted from the hydraulic to the permanent magnet synchronous motor (PMSM) drive [1-4]. As an important actuator of the robot, the electric cylinder plays an important role in the control of the robot. Therefore, the position control of the electric cylinder has gradually become a hot research topic, which has attracted wide attention. Because of its high performance such as simple structure, high precision, high power density, high torque to inertia ratio, smooth motion, low noise, and high efficiency, the electric servo system is widely used in robot control [5], medical equipment [6], precision control [7], automotive electronics [8], and other industries [9].

A variety of methods were adopted by many scholars to control the PMSM. Adaptive control [10-14], model predictive control [15-17], fractional order control [18, 19], and sliding mode control [20] are used to solve model uncertainties. These algorithms have improved the control performance of permanent magnet synchronous motor from different aspects.

However, there are some defects that cannot be avoided in the electric servo system, so it is not easy to get better control precision. These defects mainly include model uncertainties [21], external disturbance $[17,22]$, and measurement noise [23]. The model uncertainties are divided into structural uncertainties (model parameter uncertainties and unmodel dynamics) and nonstructural uncertainties (nonlinear friction, load variant, nonlinear saturation, and dead zone). These uncertainties seriously affect the control accuracy of the system and even cause the system to be uncontrollable. How to reduce the influence of these nonlinear factors on the control system and simplify the control system has been the goal of the researches in the control field. Control algorithms mentioned in [10-19] need to establish a more accurate mathematical model. Furthermore, in real industrial application 


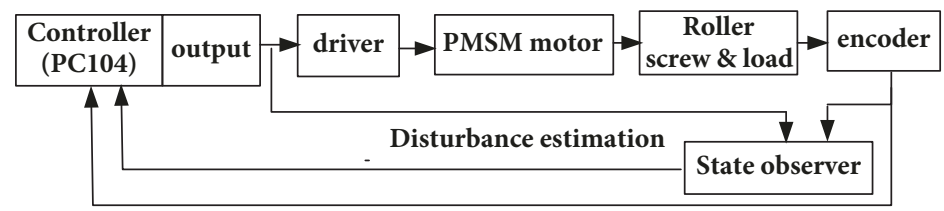

FIGURE 1: The electric cylinder position tracking system structure diagram.

environment, friction model changes with the variation of the motion state. In fact, it is hard to set up these system models. Therefore, we use active disturbance rejection control technology to solve the problem of uncertain interference in the system.

20 years ago, Jingqing Han proposed the active disturbance rejection control (ADRC) algorithm, which needs less quantity of model information. ADRC consists of tracking differentiator (TD), extended state observer (ESO), and feedback controller based on state error. Not knowing exactly system model, we only need its output and input of information and ESO can estimate the external disturbance and internal perturbation [24-26].

Due to the fact that the sliding mode control has many advantages, such as fast response, robustness to parameter variations and external disturbances, and simple realization, sliding model control (SMC) has been widely used in robot, aircraft, and so on $[27,28]$. The conventional sliding model control is linear, whose system tracking error cannot converge to zero within a fixed time, while terminal sliding mode control (TSMC), which has a nonlinear switching manifold, has high performance that can reach the equilibrium in finite time $[22,29]$. Unfortunately, when the system state is far away from the equilibrium, its convergence rate is slow. So, $\mathrm{Yu}$ and Man proposed the fast terminal sliding mode control (FTSMC) [30]. However, in real application, there is a singularity problem in some domain. Hence, nonsingular fast terminal sliding mode control was proposed [31].

In this paper, we developed a fast terminal sliding mode control algorithm to ensure that the system can achieve equilibrium point in finite time. Besides, a novel disturbance observer that needs less system model information was introduced to estimate the internal interference and external perturbation. In addition, we proposed a tracking differentiator, which was used to attenuate the measurement noise of the output. The tracking differentiator greatly improved the system performance.

This paper is organized as follows: Section 2 describes the principle of the system. The model of the system is established in Section 3. Controller is designed in Section 4 and the controller algorithm is simulated and verified in Section 5. Section 6 summarizes the whole paper.

\section{System Working Principle}

Figure 1 is the electric cylinder position tracking system structure diagram. The whole system is composed of PC104, motor driver, PMSM motor, roller screw and variable load, and photoelectric encoder. Numerical control technology was used in the position loop of the system. Working principle of the system is as follows: computing the error value between the reference input and current state feedback value from encoder. Then, the control input value was calculated by the investigated control algorithm that was based on the error value. Finally, after the D/A conversion and signal processing, the control input is transferred to the motor driver and controls the motor running and the system can achieve position tracking effectively within a certain period of time.

\section{System Modeling}

From aforementioned statement, we can know that the system is second-order nonlinear uncertainty system, whose equation the following:

$$
\begin{aligned}
& \dot{x}_{1}=x_{2} \\
& \dot{x}_{2}=f\left(x_{1}, x_{2}\right)+d\left(x_{1}, x_{2}, t\right)+a(x) u
\end{aligned}
$$

In (1), $\left(x_{1}, x_{2}\right)$ is the system state variable vector, $x_{1}, x_{2}$ represent position and velocity, respectively. $f\left(x_{1}, x_{2}\right)$ and $a(x)$ are smooth continuous nonlinear functions that take $\left(x_{1}, x_{2}\right)$ as the independent variables. $d\left(x_{1}, x_{2}, t\right)$ are the uncertainties (i.e., external perturbation and parameter uncertainties), which are bounded by $\left|f\left(x_{1}, x_{2}\right)\right| \leq f$ and $\left|d\left(x_{1}, x_{2}\right)\right| \leq d$. $u$ is control input of the system.

\section{NFTSM Controller Design with ESO}

Control objective of the system is to design a robust controller so that the electric cylinder can track desired input signal accurately and rapidly in the presence of model uncertainty and external disturbance. In order to satisfy design demands, a design method of controller is proposed. The structure of the controller is designed to be as shown in Figure 2. Generally speaking, the controller is composed of two parts: extended state observer and nonsingular fast terminal sliding mode controller (NFTSM). The following will be discussed separately.

4.1. Extended State Observer. The extended state observer does not depend on the specific mathematical model of the disturbance, nor does it need to measure its effect directly. Its structure is shown in Figure 3.

In our electric cylinder position tracking system, $f\left(x_{1}, x_{2}\right)$, which is bounded and continuously differentiable, is composed of high-order unmodeling dynamics and friction. $d\left(x_{1}, x_{2}, t\right)$ include load variation and external 


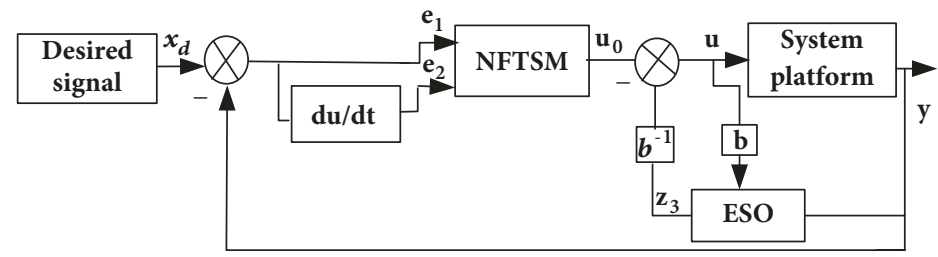

FIGURE 2: System controller structure diagram.

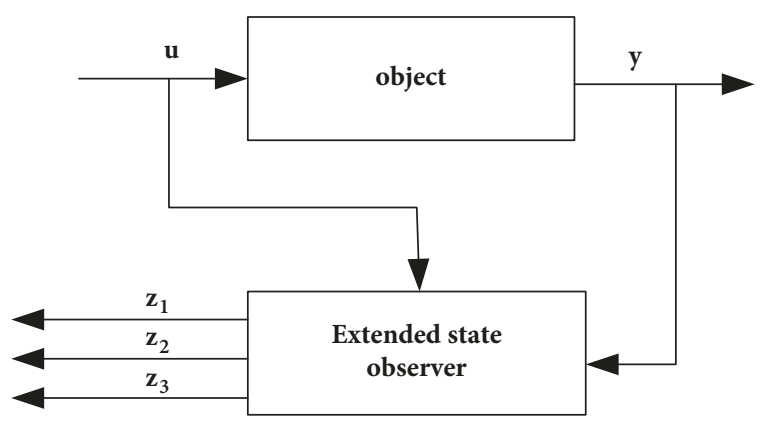

FIGURE 3: Extended state observer structure diagram.

perturbation. The ESO defines the internal uncertainty $f\left(x_{1}, x_{2}\right)$ and the external uncertainty as lump extended state $x_{3}$.

$$
x_{3}=f\left(x_{1}, x_{2}\right)+d\left(x_{1}, x_{2}, t\right)
$$

Suppose that $\dot{x}_{3}=m(t)$. So we can rewrite the system state equation as follows:

$$
\begin{aligned}
& \dot{x}_{1}=x_{2} \\
& \dot{x}_{2}=x_{3}+a u \\
& \dot{x}_{3}=m(t) \\
& y=x_{1}
\end{aligned}
$$

The ESO of the system is designed as follows:

$$
\begin{aligned}
e & =z_{1}-y \\
\dot{z}_{1} & =z_{2}-\lambda_{1} e \\
\dot{z}_{2} & =z_{3}-\lambda_{2} f a l\left(e, \beta_{1}, \delta\right)+a u \\
\dot{z}_{3} & =-\lambda_{3} f a l\left(e, \beta_{2}, \delta\right) \\
f a l(e, \beta, \delta) & = \begin{cases}\frac{e}{\delta^{\beta-1}} & |e| \leq \delta \\
|e|^{\beta} \operatorname{sign}(e) & |e|>\delta\end{cases}
\end{aligned}
$$

where state variables $z_{1}, z_{2}, z_{3}$ are the observation values of $x_{1}, x_{2}, x_{3}$, respectively. $\lambda_{1}, \lambda_{2}, \lambda_{3}$ are the adjustable parameters of the ESO and satisfy $\lambda_{1}=3 / \mu, \lambda_{2}=3 / \mu^{2}$, and $\lambda_{3}=1 / \mu^{3}$. When debugging the system, we can tune $\mu$ so as to make $z_{i}(i=1 \sim 3)$ approximately equal to $x_{i}(i=1 \sim 3)$. Using $f a l()$ can make the system avoid high frequency flutter.
4.2. Nonsingular Fast Terminal Sliding Mode Control. In order to solve the singularity and slow convergence of traditional sliding mode control, a novel sliding mode control design, nonsingular fast terminal sliding mode control, is proposed.

4.2.1. Sliding Mode Surface Design. The tracking position and velocity error of the system are defined as $e_{1}=x_{1}-x_{d}$ and $e_{2}=$ $x_{2}-\dot{x}_{d}$, respectively, where $x_{1}, x_{2}, x_{d}$ have been defined as before. Particularly, $x_{d}$ has second derivative. Furthermore, we define the sliding mode surface as

$$
s=e_{1}+\alpha_{1} e_{1}^{q / p}+\alpha_{2} e_{2}^{h / l}
$$

where $\alpha_{1}, \alpha_{2}$ are positive parameters, $p, q, h$, and $l$ are all odd integers and $2 p>q>p$ and $1<h / l<q / p \cdot e_{1}$ and $e_{2}$ do not have negative exponent term, which ensures that the controller based on the sliding mode surface design avoids the singularity problem. When the system states arrive at sliding mode surface, $s=0$; that is to say, (6) satisfies

$$
e_{1}+\alpha_{1} e_{1}^{q / p}+\alpha_{2} e_{2}^{h / l}=0
$$

From (7), we can easily get

$$
e_{2}^{h / l}=-\frac{1}{\alpha_{2}}\left(e_{1}+\alpha_{1} e_{1}^{q / p}\right)
$$

Substituting $\dot{e}_{1}=e_{2}$ in (8) gives

$$
\begin{aligned}
\dot{e}_{1} & =-\left(\frac{1}{\alpha_{2}}\right)^{l / h}\left(e_{1}+\alpha_{1} e_{1}^{q / p}\right)^{l / h} \\
& =-\left(\frac{1}{\alpha_{2}}\right)^{l / h}\left(e_{1}\left(1+\alpha_{1} e_{1}^{q / p}\right)\right)^{l / h} \\
& =-\left(\frac{1}{\alpha_{2}}\right)^{l / h} e_{1}^{h / l}\left(1+\alpha_{1} e_{1}^{1-q / p}\right)^{l / h}
\end{aligned}
$$

Suppose that the convergence time of the system is $t$. It means that $t$ is the time required by the control system when the controller makes the initial state of the system (error is not equal to zero) reach the equilibrium point, where the error is equal to zero. The time integrate of (9) satisfies

$$
\int_{e_{1(0)}}^{e_{1(t)}} \frac{\dot{e}_{1}}{e_{1}^{l / h}} d t=-\int_{0}^{t}\left(\frac{1}{\alpha_{2}}\right)^{l / h}\left(1+\alpha_{1} e_{1}^{-1+q / p}\right)^{l / h} d t
$$


$p$ and $q$ are odd, so $p-q$ is even integer and $e_{1}^{-1+q / p} \geq$ 0 . Correspondingly, from (10), we can get the following equation:

$$
\begin{aligned}
\int_{e_{1(0)}}^{e_{1(t)}} \frac{\dot{e}_{1}}{e_{1}^{l / h}} d t & =-\int_{0}^{t}\left(\frac{1}{\alpha_{2}}\right)^{l / h}\left(1+\alpha_{1} e_{1}^{-1+q / p}\right)^{l / h} d t \\
& \leq-\int_{0}^{t}\left(\frac{1}{\alpha_{2}}\right)^{l / h} d t
\end{aligned}
$$

From (11), we can easily draw the conclusion that when the sliding surface and its parameters are determined, the tracking error of the system will converge to zero within a finite time on the sliding surface. Furthermore,

$$
t=\int_{0}^{\left|e_{0}\right|} \frac{\alpha_{2}^{l / h}}{\left(e_{1}+\alpha_{1}\left|e_{1}\right|^{q / p}\right)^{l / h}} d e_{1}
$$

Remark 1. For sliding mode surface (7), when the system state variable is in the vicinity of the equilibrium point, the position error of the system is very large and the convergence speed is only determined by the high power of the position error. While the system state variable is far away from the equilibrium point, the position error of the system is relatively small and the convergence speed is determined by the power part of the position error. Without the high-order terms error in the traditional sliding mode, NFTSM has faster convergence rate than the traditional sliding mode, which can solve the problem of slow convergence speed and improve the transient performance of the system.

Remark 2. Because the exponents of $e_{1}$ and $e_{2}$ are larger than 1 , they can avoid the negative index after derivation and thus will not produce singular problem.

4.2.2. Controller Design. Before designing the controller, we introduce Lemma 3, which plays an important role in verifying the controller stability.

Lemma 3 (Bhat and Bernstein, 1998). Suppose that $\Omega(x)$ is a $C^{1}$ smooth positive definitive function (defined on $U \subset R^{n}$ ) and $\dot{\Omega}(x)+\tau \Omega^{\gamma} \leq 0$ on $U \subset R^{n}$, for $1<\gamma<0$ and $\tau>0$; then there exists an area $U_{0} \subset R^{n}$ such that any $\Omega(x)$ that starts from $U_{0} \subset R^{n}$ can reach $\Omega(x) \equiv 0$ in finite time. Moreover, if $T_{\text {reach }}$ is the time needed to reach $\Omega(x) \equiv 0$, then $T_{\text {reach }} \leq$ $\Omega^{1-\gamma}\left(x_{0}\right) / \tau(1-\gamma)$, where $\Omega\left(x_{0}\right)$ is the initial value of $\Omega(x)$.

Theorem 4. For the electric cylinder position manipulator (1), if the NFSTM manifold is chosen as (7) and the NFTSM control is designed as follows, the tracking position error can converge to zero in finite time.

$$
\begin{aligned}
u= & -a^{-1}\left(\frac{1}{\alpha_{2}} \frac{l}{h} e_{2}^{2-(h / l)}+\frac{\alpha_{1}}{\alpha_{2}} \frac{l}{h} \frac{q}{p} e_{1}^{q / p-1} e_{2}^{2-(h / l)}\right. \\
& \left.+z_{3}(x, t)-\ddot{x}_{d}+M \operatorname{sgn}(s)\right)
\end{aligned}
$$

where $e_{1}=x_{1}-x_{d}, e_{2}=\dot{e}_{1}=x_{2}-\dot{x}_{d}$, and $x_{1}$ and $x_{2}$ are the state variables, as defined previously. $z_{3}$ is the estimated value of the system lumped disturbance. $M$ is the controller switching gain.

Proof. Construct the following Lyapunov function:

$$
V=0.5 s^{2}
$$

Differentiating $s$ with respect to time, we get (15):

$$
\dot{s}=e_{2}+\alpha_{1} \frac{q}{p} e_{1}^{q / p-1} e_{2}+\alpha_{2} \frac{h}{l} e_{2}^{h / l-1} \dot{e}_{2}
$$

Differentiating $V$ with respect to time and substituting (15) into it, the yield is

$$
\begin{aligned}
\dot{V} & =s\left(e_{2}+\alpha_{1} \frac{q}{p} e_{1}^{q / p-1} e_{2}+\alpha_{2} \frac{h}{l} e_{2}{ }^{h / l-1} \dot{e}_{2}\right) \\
& =s\left(e_{2}+\alpha_{1} \frac{q}{p} e_{1}^{q / p-1} e_{2}+\alpha_{2} \frac{h}{l} e_{2}{ }^{h / l-1}\left(\dot{x}_{2}-\ddot{x}_{d}\right)\right)
\end{aligned}
$$

Substituting (1) into above formula,

$$
\begin{aligned}
\dot{V} & =s\left(e_{2}+\alpha_{1} \frac{q}{p} e_{1}^{q / p-1} e_{2}+\alpha_{2} \frac{h}{l}\right. \\
& \left.\cdot e_{2}^{h / l-1}\left(f\left(x_{1}, x_{2}\right)+d\left(x_{1}, x_{2}, t\right)+a u-\ddot{x}_{d}\right)\right) \\
& =s\left(e_{2}+\alpha_{1} \frac{q}{p} e_{1}^{q / p-1} e_{2}+\alpha_{2} \frac{h}{l}\right. \\
& \left.\cdot e_{2}^{h / l-1}\left(\omega(x, t)+a u-\ddot{x}_{d}\right)\right)=s \alpha_{2} \frac{h}{l} e_{2}^{h / l-1}\left(\frac{1}{\alpha_{2}}\right. \\
& \cdot \frac{l}{h} e_{2}^{2-h / l}+\frac{\alpha_{1}}{\alpha_{2}} \frac{q}{p} \frac{l}{h} e_{1}^{q / p-1} e_{2}^{2-h / l} \\
& \left.+\left(\omega(x, t)+a u-\ddot{x}_{d}\right)\right)
\end{aligned}
$$

Substituting (13) into above formula,

$$
\begin{aligned}
\dot{V} & =s \alpha_{2} \frac{h}{l} \\
& \cdot e_{2}^{h / l-1}\left(f(x, t)+d(x, t)-z_{3}(x, t)-M \operatorname{sgn}(s)\right) \\
& <s \alpha_{2} \frac{h}{l} e_{2}^{h / l-1}\left(f+d-z_{3}-M \operatorname{sgn}(s)\right)
\end{aligned}
$$

Because $h, l$ are positive odd integers and $1<h / l<2$ and $\alpha_{2}>0, s \alpha_{2}(h / l) e_{2}{ }^{h / l-1}>0$. In order to make the system keep stability, only if $M$ satisfies $M>f+d-z_{3}$, that is, $\dot{V}$ satisfies $\dot{V}<0$, we have

$$
\dot{V}<-k|s|=-\sqrt{2} k V^{0.5}
$$

Hence,

$$
\dot{V}+k V^{0.5}<0 \quad(k>0)
$$


From Lemma 3, it is obvious that the control system is stable and that reaching the sliding mode surface in finite time also can be obtained. Besides, according to the characteristics of the sliding surface, we have previously obtained that when the error reaches the sliding surface, it can converge to zero in limited time. Verification is completed.

Remark 5. In fact, $f+d-z_{3}$ is the estimation error of the system lumped disturbance (suppose that $f+d-z_{3}=$ $\varepsilon)$. Obviously, $\varepsilon$ is much smaller than the system lumped disturbance $(f+d)$, so the system switching gain $(M)$ in the control law can be designed as much smaller as possible only if it satisfies Lyapunov stability condition $(\dot{V}<0)$. Hence, the chattering of the system can be effectively suppressed, which greatly improves the dynamic performance of the system. Comparing Figure 8(a) and Figure 9(a), we can see that the tracking differentiator can improve the dynamic performance of the system.

Remark 6. In order to simplify the design of the system controller, we do not take into account the system output noise on the system tracking performance when we propose the controller before. Simulation results show that the tracking differentiator, which is added at the output of the system, can improve the tracking accuracy of the system.

Tracking differentiator is such a device: for a given input signal (e.g., $x_{d}$ ), its output signals satisfy that $X_{1}$ tracks $x_{d}$ and $X_{2}$ is used as approximate differentiator of $\dot{x}_{d}$. Under normal condition, the differential signal is acquired by the backward difference of the reference input signal. Tracking differentiator has two functions:

(1) It can extract continuous signal and differential signal from the measured signal with discontinuous or random noise.

(2) It can realize the fast tracking of the input reference signal and improve the response speed of the system through adjusting the device's parameter.

One feasible second-order tracking differentiator can be designed as follows:

$$
\begin{aligned}
& \dot{x}_{1}=x_{2} \\
& \dot{x}_{2}=\operatorname{fhan}\left(x_{1}-x_{d}, x_{2}, r, h_{0}\right)
\end{aligned}
$$

where $r$ and $h_{0}$ are adjustable parameters, which decide the device's transient performance. $r$ is speed factor and it determines the size of the tracking speed. The tracking speed increases with the value of $r . h_{0}$ is filter coefficient. We all know that the reduction of the integral step has great effect on the noise suppression. While the step is constant value, enlarging filter coefficient is an effective way to enhance the filter effect. However, the parameters are bounded actually and only in the adjustable range is the transient performance acquired. $\operatorname{fhan}\left(x_{1}-x_{d}, x_{2}, r, h_{0}\right)$ is defined as formula (14).

$$
\begin{aligned}
& a_{0}=h_{0} x_{2}, \\
& d=r h_{0}{ }^{2}, \\
& y=\left(x_{1}-x_{d}\right)+a_{0}
\end{aligned}
$$

TABLE 1: System model components parameters.

\begin{tabular}{lc}
\hline Parameters & Value \\
\hline Ball screw thread diameter & $9.5 \mathrm{~mm}$ \\
Thread lead & $5.08 \mathrm{~mm}$ \\
Ball screw static friction coefficient & 0.3 \\
Ball screw Coulomb friction coefficient & 0.15 \\
Contact stiffness of ball screw & $1 \times 10^{9} \mathrm{~N} / \mathrm{m}$ \\
Stribeck friction coefficient & $0.06 \mathrm{~m} / \mathrm{s}$ \\
Screw mass & $0.17 \mathrm{~kg}$ \\
Moment of inertia of rotating load & $6 \times 10^{-5} \mathrm{kgm}$ \\
Viscous friction coefficient of rotating & $6 \times 10^{-5} \mathrm{Nm}^{2}(\mathrm{rev} / \mathrm{min})$ \\
load & $(-0.06,0.06) \mathrm{Nm}$ \\
Disturbance torque & $0.005 \mathrm{~ms}$ \\
Step &
\end{tabular}

$$
\begin{aligned}
a_{1} & =\sqrt{d(d+8|y|)} \\
a_{2} & =\frac{\operatorname{sign}(y)\left(a_{1}-d\right)}{2}+a_{0} \\
f_{s g} & =\frac{(\operatorname{sign}(y+d)-\operatorname{sign}(y-d))}{2} \\
a & =\left(a_{0}+y-a_{2}\right) f s g+a_{2} \\
s_{a} & =\frac{(\operatorname{sign}(a+d)-\operatorname{sign}(a-d))}{2} \\
\text { fhan } & =-r\left(\frac{a}{d}-\operatorname{sign}(a)\right) s_{a}-r \operatorname{sign}(a)
\end{aligned}
$$

Measurement noise and actuator default are also important factors to the tracking performance of the control system. According to the principle of absolute invariance, two kinds of method can be used to eliminate or weaken the measurement noise and actuator. When we know the model of the system, we can adopt Kalman observer to estimate the value of measurement. While the system model cannot be obtained, RC filter and other filtering methods were used. In this paper, without knowing the exact model of the system, we select tracking differentiator to depress the measuring noise and actuator default. With appropriate adjustment parameters $r, h_{0}$, the noise can be removed.

\section{System Simulation and Experimental Verification}

5.1. System Simulation. For the electric cylinder position servo tracking system, whose model is shown as (1), we use AMESim software to build mechanical model of the system, using Simulink to set up the model of the control part as well. Figure 4 and Table 1 are AMESim and Simulink cosimulation system model diagram and simulation parameters table, respectively. 


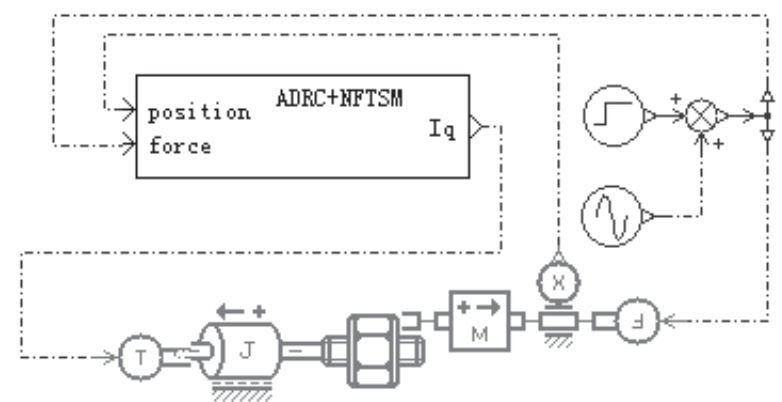

FIgURE 4: AMESim and Simulink cosimulation system model diagram.

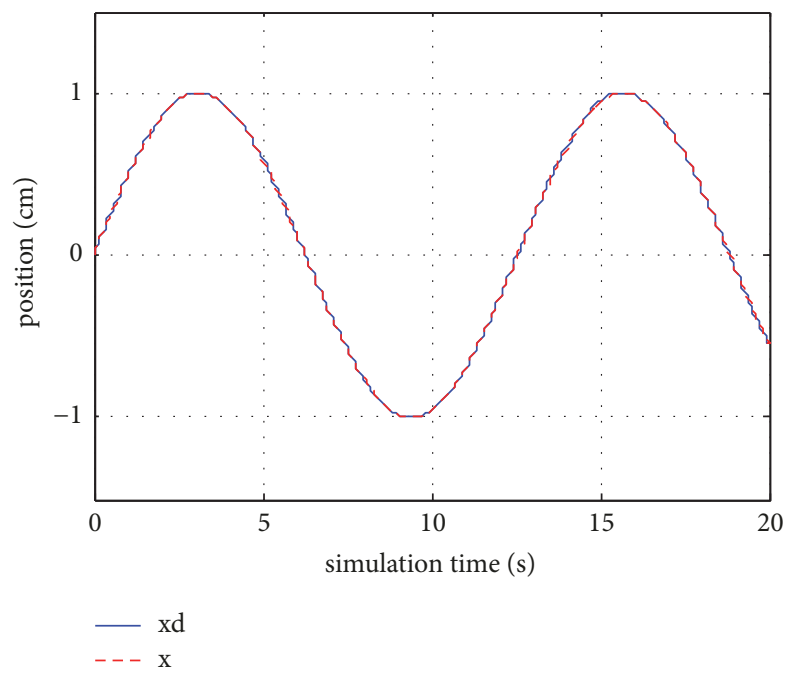

(a)

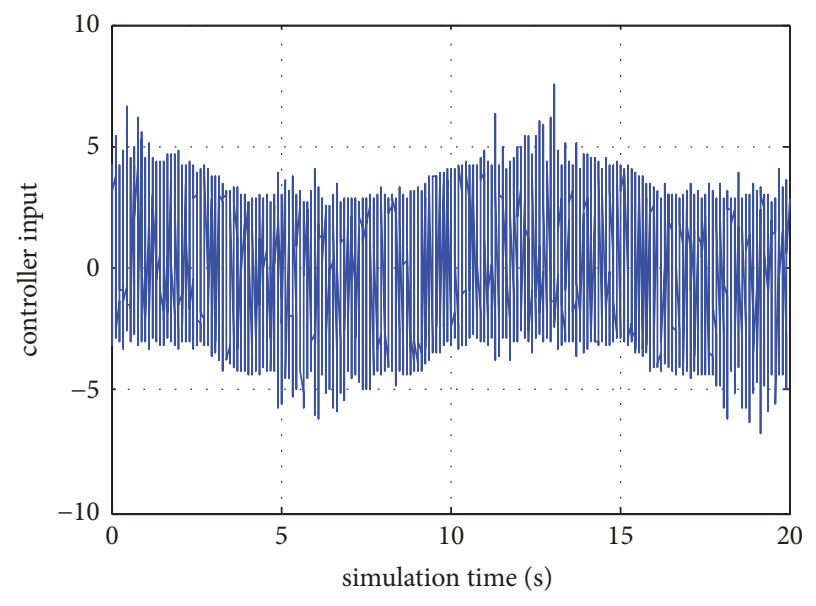

u

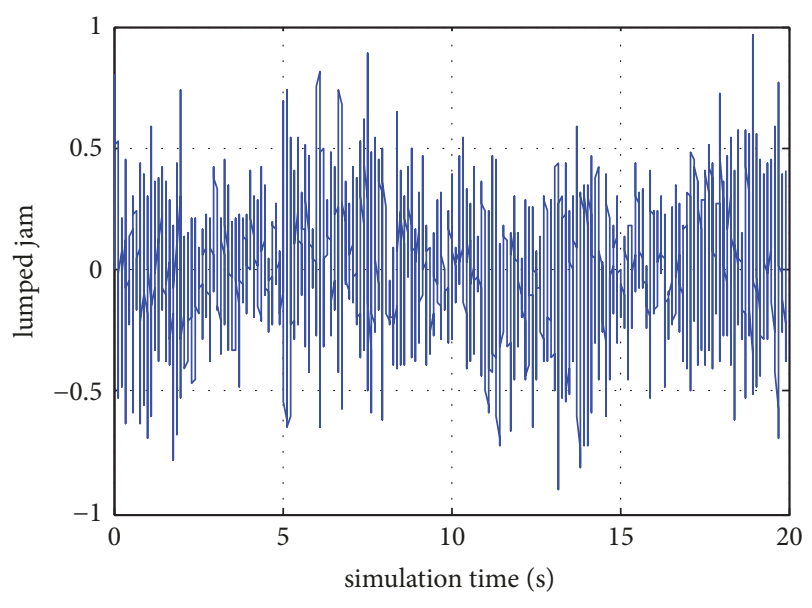

$-\mathrm{z} 3$

(b)

(c)

FIGURE 5: The system performance ADRC+NFTSM under constant load with sinusoidal reference input. 


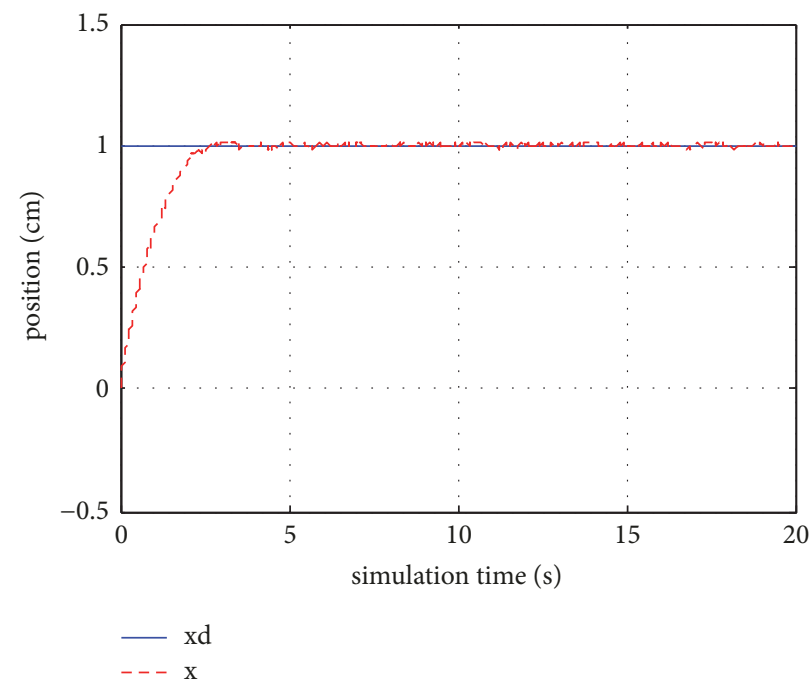

FIGURE 6: The system performance of ADRC+NFTSM under constant load with step reference input.

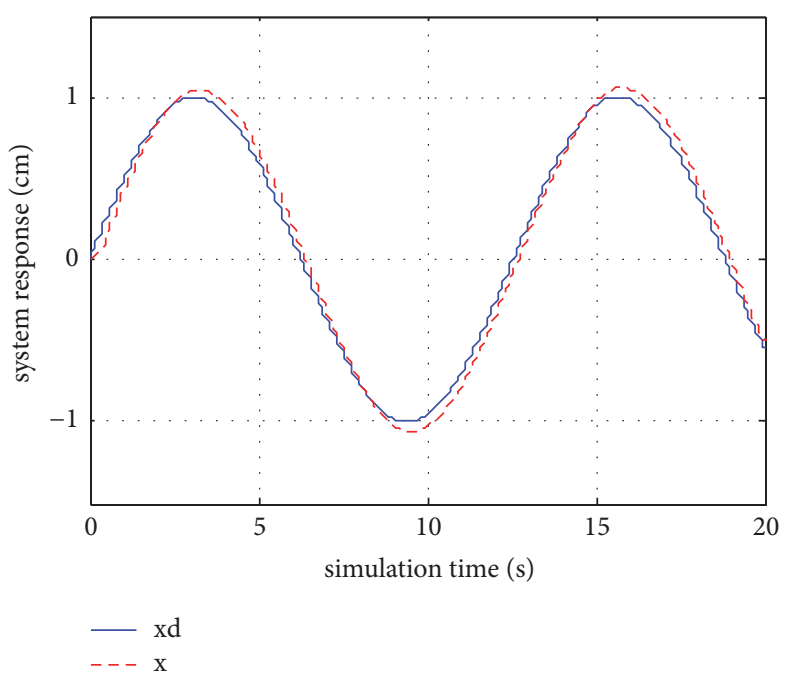

(a)

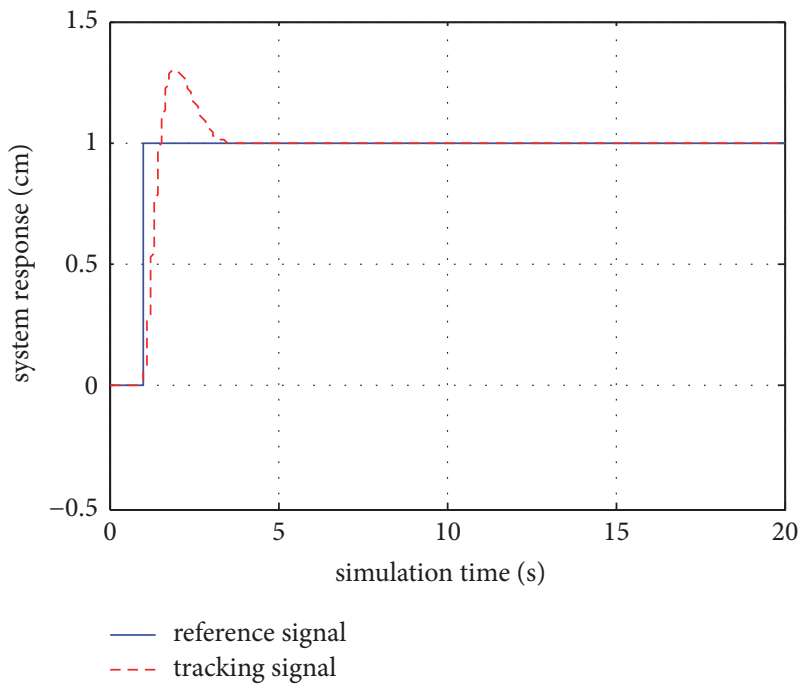

(b)

FIGURE 7: The system performance of PID under constant load with step reference input.

The simulation results with $0.5 \mathrm{~Hz}$ sinusoidal reference signal and unit step signal of the ADRC algorithm based on NFTSM have been shown in Figures 5 and 6. Figure 5(a) illustrates that the system output $\mathrm{x}$ can track the reference signal smoothly with about 2 3\% tracking error except some fluctuation in $0 \sim 1$ second, while the tracking error of the PID algorithm (Figure 7(a)) is bigger than Figure 5(a). Figure 5(b) shows that the amount of control $u$ varies periodically with external disturbance (Figure 5(c)).

Figure 6 illustrates the simulation result of system tracking unit step signal. Figure 6 illustrates that the output of the system $x$ tracks the reference signal $x_{d}$ very well, while the tracking performance of the PID algorithm is bad (Figure 7(b)).
Figures 8 and 9 illustrate the performance of the system in the case of noise suppression. Figure 8 is the tracking performance of the tracking differentiator added to the output of the system, while Figure 9 is the one without tracking differentiator. Figures 8 (b) and $9(\mathrm{~b})$ are the system original output. Figure 8(c) is the system output after tracking differentiator filtering. By comparison, we can see that the tracking effect of the system is improved obviously when we add TD to the signal output end of the system.

5.2. Experimental Verification. In order to verify the feasibility of the proposed fast terminal sliding mode controller with an extended state observer, as shown in Figure 10, an experimental platform is built, which consists of permanent 


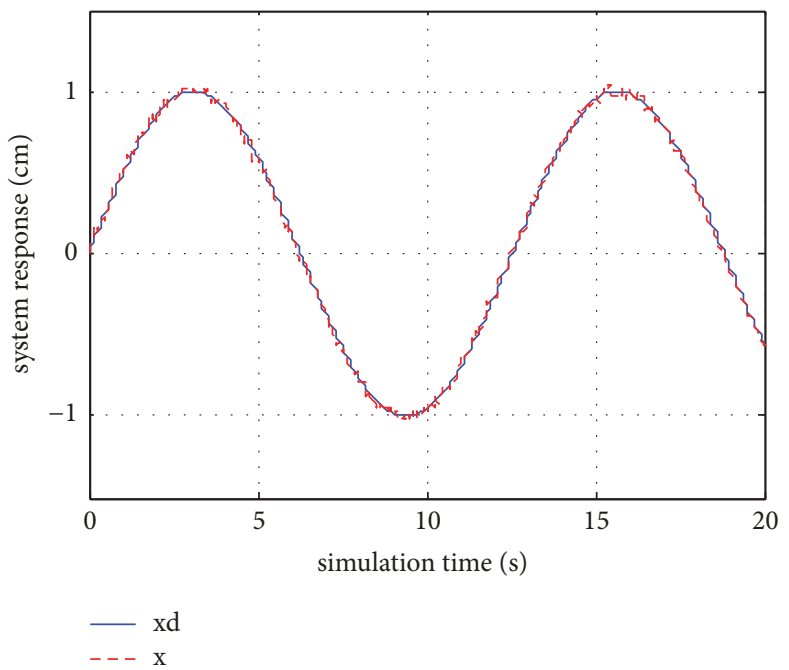

(a)

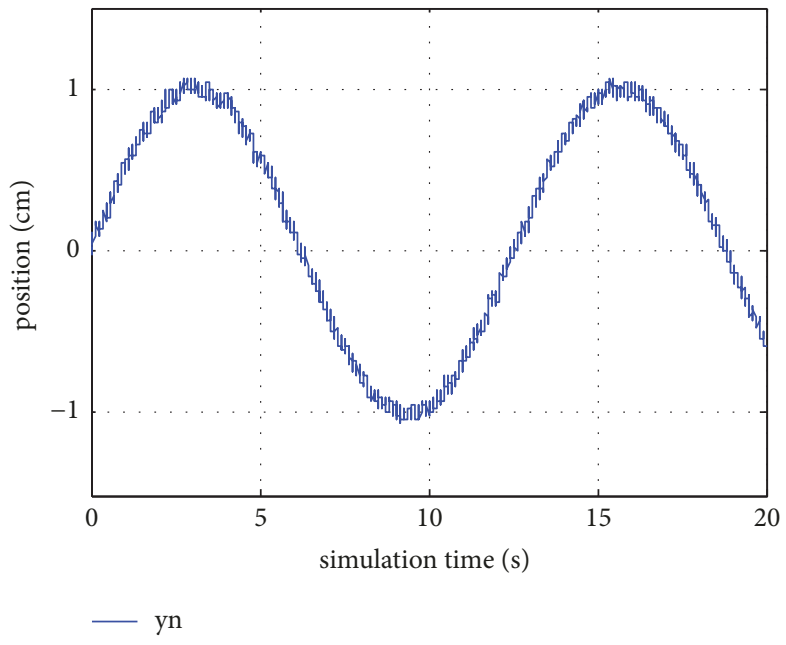

(b)

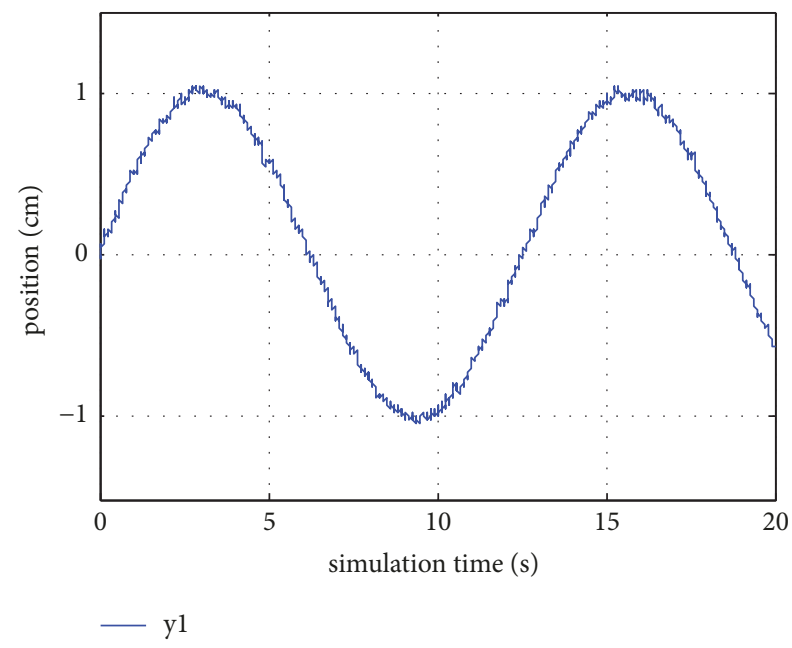

(c)

FIGURE 8: The system performance of ADRC+NFTSM under measurement noise suppression with sine reference input.

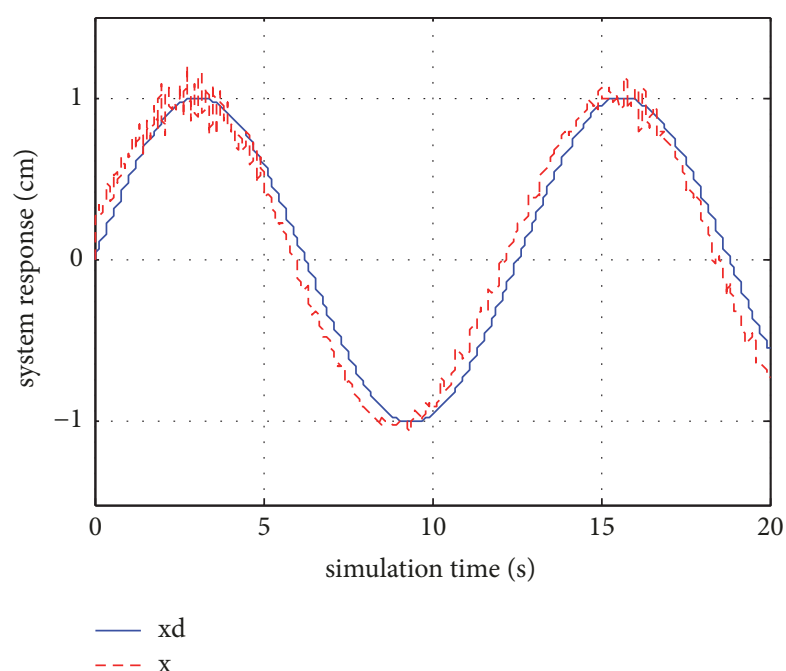

(a)

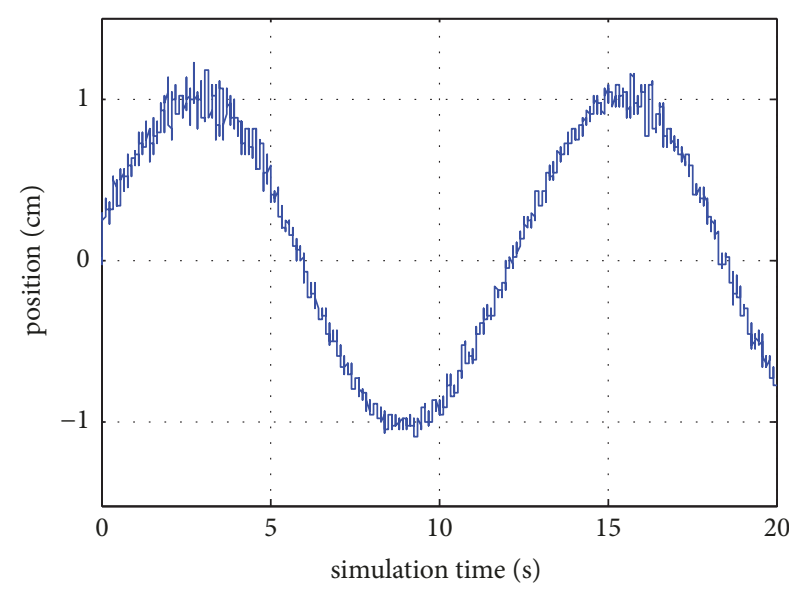

- yn

FIGURE 9: The system performance of ADRC+NFTSM without measurement noise suppression with sine reference input. 


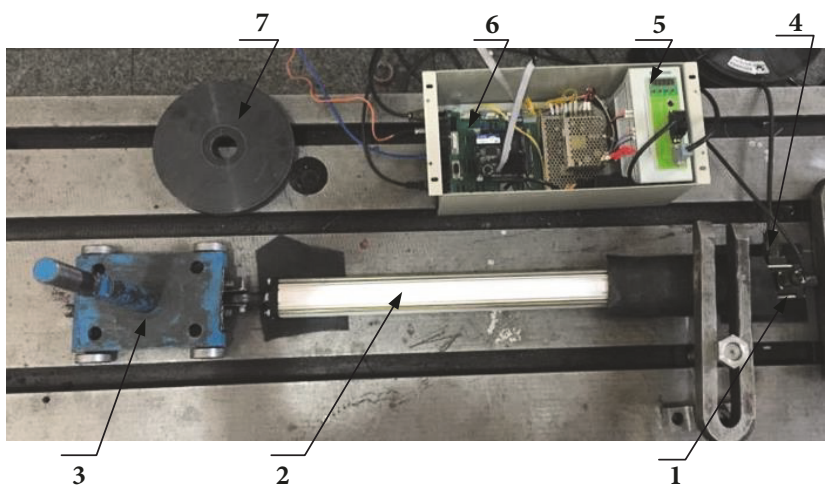

1, PMSM; 2, electric cylinder; 3, load (vehicle); 4, optical encode;

5, driver; 6, controller; 7 , load (weight)

FIGURE 10: Experimental platform.

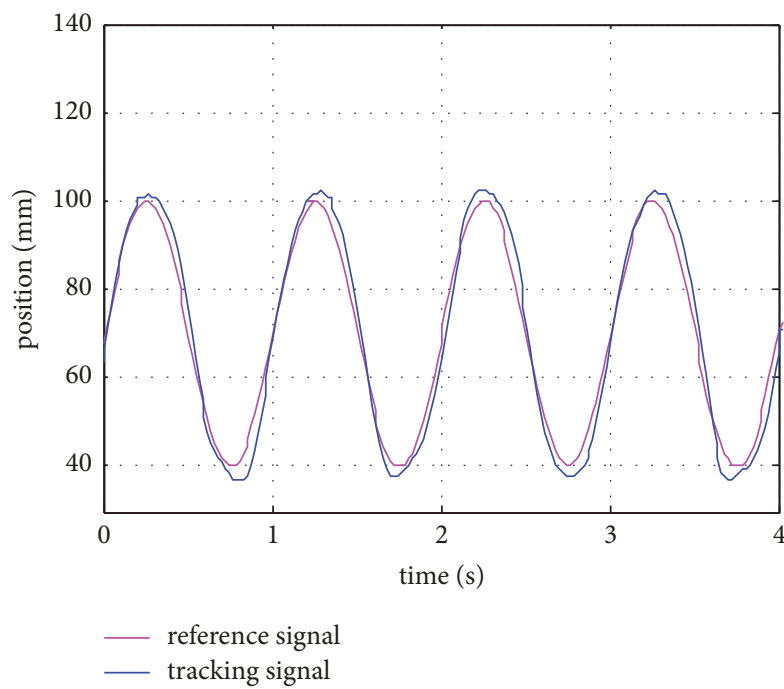

(a) (NFTSM)

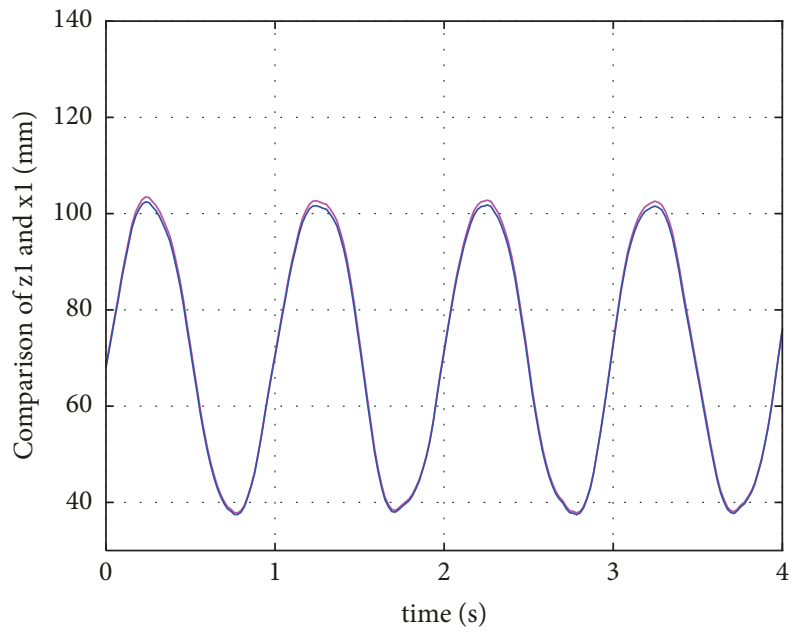

$-\mathrm{z} 1$

(c) (Comparison curve of $\mathrm{zl}$ to $\mathrm{xl}$ )

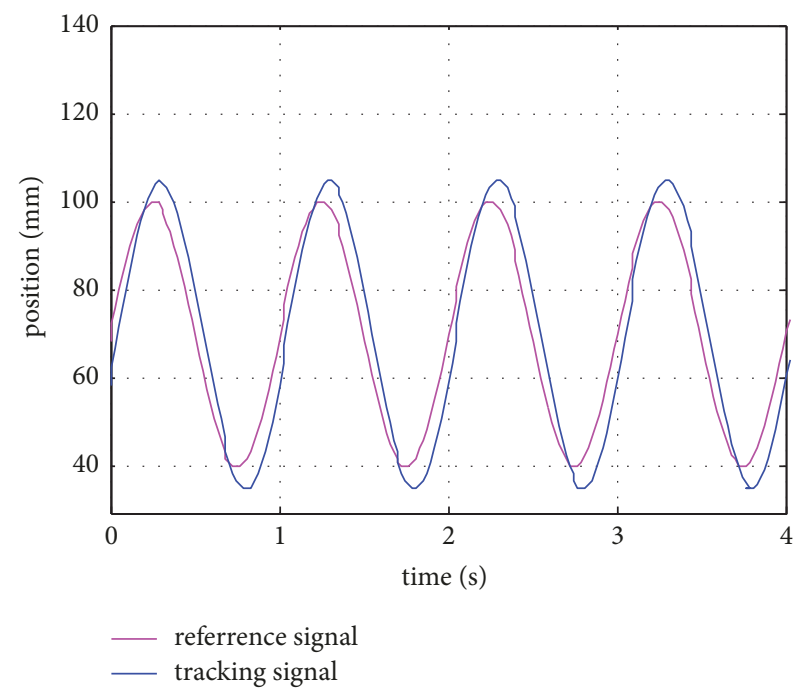

(b) (PID)

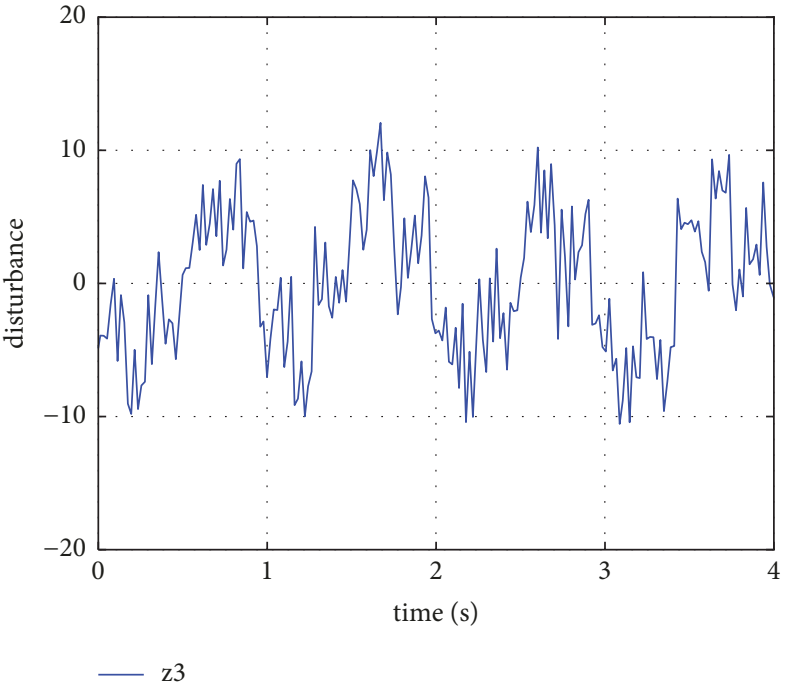

(d) (The estimation value of disturbance)

FIGURE 11: Tracking performance comparison of Case 1. Case 1 refers to the situation when the load of the system is the only vehicle. 


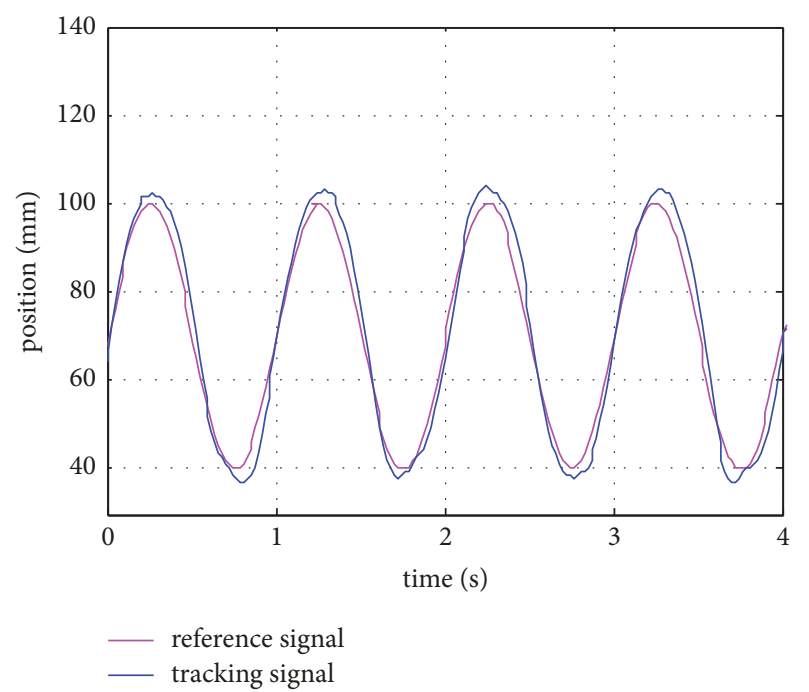

(a) (NFTSM)

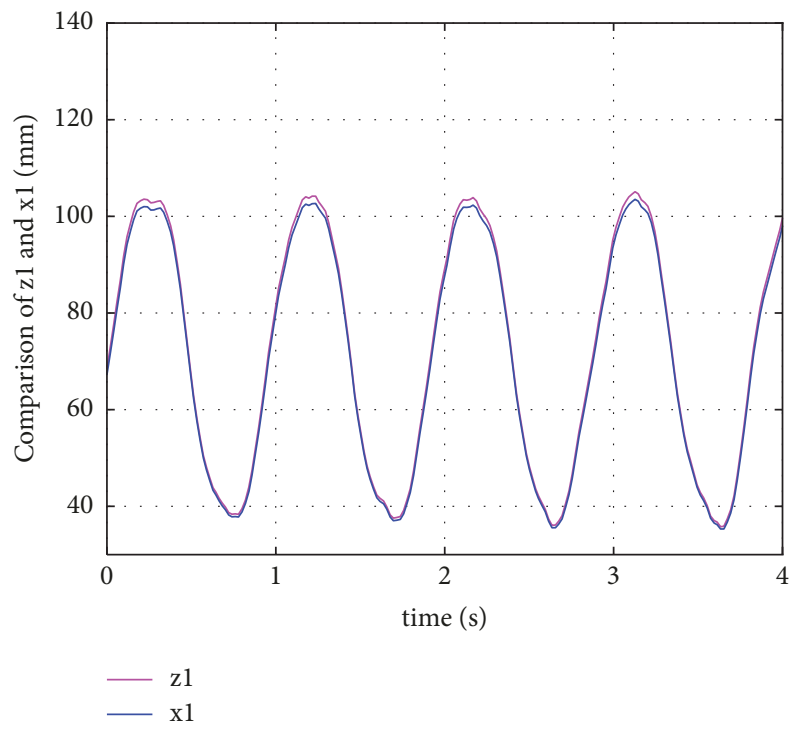

(c) (Comparison curve of $\mathrm{zl}$ to $\mathrm{xl}$ )

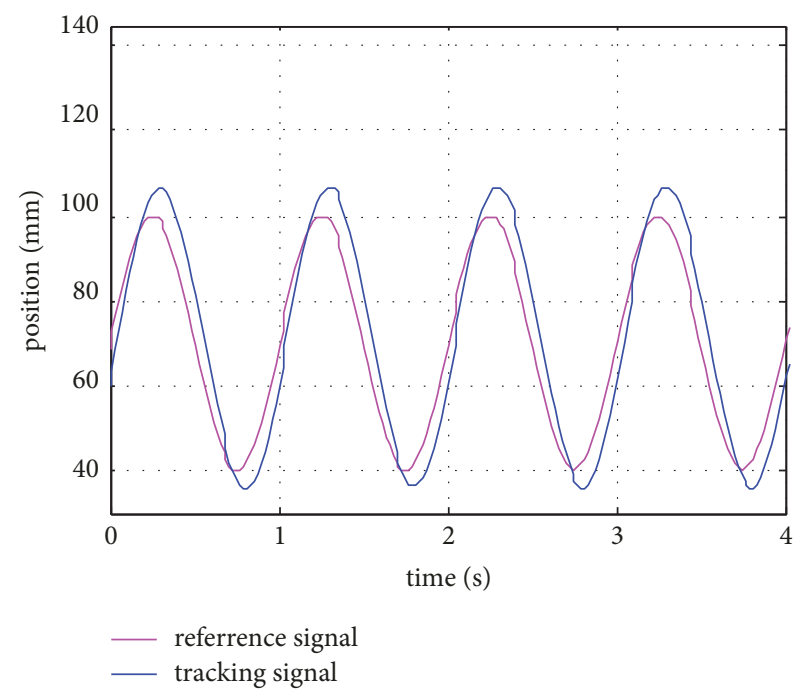

(b) (PID)

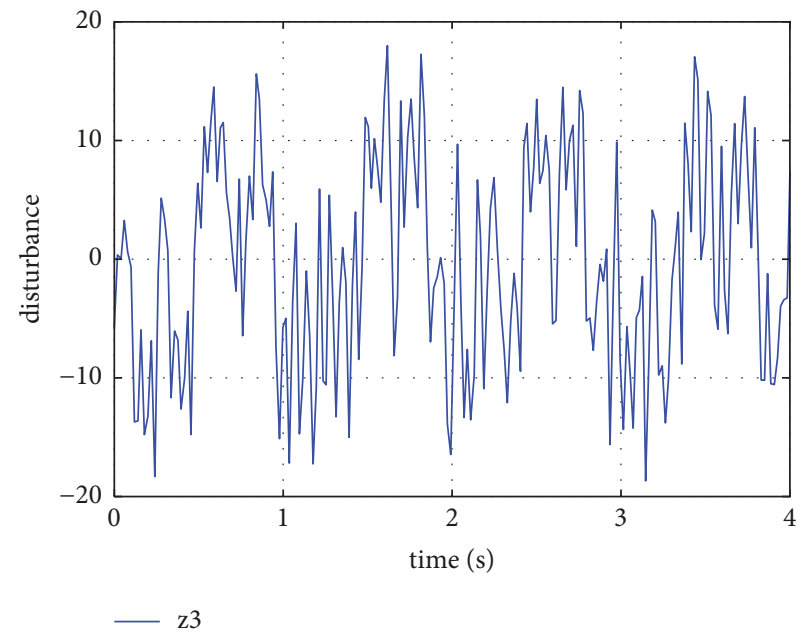

(d) (The estimation value of disturbance)

FIGURE 12: Tracking performance comparison of Case 2. Case 2 refers to the situation when the load of the system is the vehicle and weight. They are two different loads of the system during the experiment.

magnet synchronous motor, electric cylinder, load, optical encode, driver, and controller. The main parameters of the motor are as follows:
(1) Rated power: $400 \mathrm{w}$.
(2) Rated torque: $1.27 \mathrm{Nm}$.
(3) Rated speed: $3000 \mathrm{r} / \mathrm{m}$.
(4) Motor rotor inertia: $0.0003 \mathrm{Nm}$.

We compare the tracking performance of the PID algorithm with the NFTSM+ESO algorithm under two different operating conditions as follows. The reference input is $70+30 \sin 2$ $\pi \mathrm{t}(\mathrm{mm})$

Case 1. The load of the system is the only vehicle.
Case 2. The load of the system is the vehicle and weight.

Case 1. Figure 11 plots the reference inputs of the two algorithms and their corresponding outputs. As seen, the control algorithm of NFTSM with ESO has better tracking performance than the PID in transient and steady-state performance. The main reason is that the ESO can estimate the disturbance of the system and compensate it in real time.

Case 2. In order to further verify the robustness of the proposed algorithm under load disturbances, we add a weight to the vehicle. The tracking performance comparison of the two algorithms is shown in Figure 12. For the same reason, NFTSM algorithm has better tracking performance than PID algorithm. 
In addition, from (c) and (d) of Figures 11 and 12, it can be seen that $\mathrm{zl}$ can realize real-time estimation of the system state $\mathrm{x} 1$. Hence, we can think that $\mathrm{z} 3$ is approximately equal to the external disturbance of the system.

\section{Conclusion}

The electric cylinder position servo system may face the case of the model uncertainty, external disturbance, and measurement noise. Comparing the simulation result of the NFTSM with ESO to the PID, we can easily draw a conclusion that the former has good dynamic and steady performance. ESO is utilized to estimate the lumped disturbance (both internal interference and external perturbation) and compensated it in the feed forward loop. Furthermore, the TD is designed to attenuate the measurement noise in the system output. The above methods can effectively improve the tracking accuracy and tracking velocity of the electric cylinder.

\section{Data Availability}

The data used to support the findings of this study are available from the corresponding author upon request.

\section{Conflicts of Interest}

The authors declare that there are no conflicts of interest.

\section{Acknowledgments}

This work was supported by the National Natural Science Foundation of China (G61503027).

\section{References}

[1] M. H. Raibert, Legged Robots That Balance, vol. 3, MIT Press, Cambridge, MA, USA, 1986.

[2] T. Boaventura, J. Buchli, C. Semini, and D. G. Caldwell, "ModelBased Hydraulic Impedance Control for Dynamic Robots," IEEE Transactions on Robotics, vol. 31, no. 6, pp. 1324-1336, 2015.

[3] J. Yao, Z. Jiao, D. Ma, and L. Yan, "High-accuracy tracking control of hydraulic rotary actuators with modeling uncertainties," IEEE/ASME Transactions on Mechatronics, vol. 19, no. 2, pp. 633-641, 2014.

[4] B. Na, H. Choi, and K. Kong, "Design of a direct-driven linear actuator for a high-speed quadruped robot, cheetaroidI," IEEE/ASME Transactions on Mechatronics, vol. 20, no. 2, pp. 924-933, 2015.

[5] S. Wen, G. Qin, B. Zhang, H. Lam, Y. Zhao, and H. Wang, "The study of model predictive control algorithm based on the force/position control scheme of the 5-DOF redundant actuation parallel robot," Robotics and Autonomous Systems, vol. 79, pp. 12-25, 2016.

[6] J.-S. Ko, T.-H. Lee, K.-G. Kim, and I.-D. Kim, "Precision speed control of PMSM for stimulation of the vestibular system using rotatory chair," Mechatronics, vol. 13, no. 5, pp. 465-475, 2003.

[7] X. Song, J. Fang, and B. Han, "High-Precision Rotor Position Detection for High-Speed Surface PMSM Drive Based on Linear Hall-Effect Sensors," IEEE Transactions on Power Electronics, vol. 31, no. 7, pp. 4720-4731, 2016.
[8] C. Choi and W. Lee, "Analysis and compensation of time delay effects in hardware-in-The-loop simulation for automotive PMSM drive system," IEEE Transactions on Industrial Electronics, vol. 59, no. 9, pp. 3403-3410, 2012.

[9] T. H. Liu, P. U. Pu, and C. K. Lin, "Implementation of an adaptive position control system of a permanent-magnet synchronous motor and its application," IET Electric Power Applications, vol. 4, no. 2, pp. 121-130, 2010.

[10] S.-K. Kim, J.-S. Lee, and K.-B. Lee, “Offset-Free Robust Adaptive Back-Stepping Speed Control for Uncertain Permanent Magnet Synchronous Motor," IEEE Transactions on Power Electronics, vol. 31, no. 10, pp. 7065-7076, 2016.

[11] J. Hu, Y. Qiu, and H. Lu, "Adaptive robust nonlinear feedback control of chaos in PMSM system with modeling uncertainty," Applied Mathematical Modelling: Simulation and Computation for Engineering and Environmental Systems, vol. 40, no. 19-20, pp. 8265-8275, 2016.

[12] S. Li and Z. Liu, "Adaptive speed control for permanent-magnet synchronous motor system with variations of load inertia," IEEE Transactions on Industrial Electronics, vol. 56, no. 8, pp. 30503059, 2009.

[13] L. Lu, B. Yao, Q. Wang, and Z. Chen, "Adaptive robust control of linear motors with dynamic friction compensation using modified LuGre model," Automatica, vol. 45, no. 12, pp. 28902896, 2009.

[14] J. Zhou and Y. Wang, "Adaptive backstepping speed controller design for a permanent magnet synchronous motor," IEE Proceedings Electric Power Applications, vol. 149, no. 2, pp. 165172, 2002.

[15] M. Siami, D. A. Khaburi, A. Abbaszadeh, and J. Rodriguez, "Robustness Improvement of Predictive Current Control Using Prediction Error Correction for Permanent-Magnet Synchronous Machines," IEEE Transactions on Industrial Electronics, vol. 63, no. 6, pp. 3458-3466, 2016.

[16] T. Turker, U. Buyukkeles, and A. F. Bakan, "A Robust Predictive Current Controller for PMSM Drives," IEEE Transactions on Industrial Electronics, vol. 63, no. 6, pp. 3906-3914, 2016.

[17] H. Liu and S. Li, "Speed control for PMSM servo system using predictive functional control and extended state observer," IEEE Transactions on Industrial Electronics, vol. 59, no. 2, pp. 11711183, 2012.

[18] W. Zheng and Y. Pi, "Study of the fractional order proportional integral controller for the permanent magnet synchronous motor based on the differential evolution algorithm," ISA Transactions $^{\circledR}$, vol. 63, pp. 387-393, 2016.

[19] B. T. Zhang and Y. G. Pi, "Enhanced robust fractional order proportional-plus-integral controller based on neural network for velocity control of permanent magnet synchronous motor," ISA Transactions ${ }^{\circledR}$, vol. 52, no. 4, pp. 510-516, 2013.

[20] Y. Feng, X. Yu, and Z. Man, "Non-singular terminal sliding mode control of rigid manipulators," Automatica, vol. 38, no. 12, pp. 2159-2167, 2002.

[21] X. G. Zhang, L. Z. Sun, K. Zhao, and L. Sun, "Nonlinear speed control for PMSM system using sliding-mode control and disturbance compensation techniques," IEEE Transactions on Power Electronics, vol. 28, no. 3, pp. 1358-1365, 2013.

[22] S. Li, M. Zhou, and X. Yu, "Design and implementation of terminal sliding mode control method for PMSM speed regulation system," IEEE Transactions on Industrial Electronics, vol. 9, no. 4, pp. 1879-1891, 2013.

[23] M. Preindl and S. Bolognani, "Model predictive direct speed control with finite control set of PMSM drive systems," IEEE 
Transactions on Power Electronics, vol. 28, no. 2, pp. 1007-1015, 2013.

[24] Y. Xia, F. Pu, M. Fu, and L. Ye, "Modeling and Compound Control for Unmanned Turret System with Coupling," IEEE Transactions on Industrial Electronics, vol. 63, no. 9, pp. 57945803, 2016.

[25] Y. Xia, L. Dai, M. Fu, C. Li, and C. Wang, "Application of active disturbance rejection control in tank gun control system," Journal of The Franklin Institute, vol. 351, no. 4, pp. 2299-2314, 2014.

[26] J. Yao, Z. Jiao, and D. Ma, "Extended-state-observer-based output feedback nonlinear robust control of hydraulic systems with backstepping," IEEE Transactions on Industrial Electronics, vol. 61, no. 11, pp. 6285-6293, 2014.

[27] H. Fukushima, K. Muro, and F. Matsuno, "Sliding-mode control for transformation to an inverted pendulum mode of a mobile robot with wheel-arms," IEEE Transactions on Industrial Electronics, vol. 62, no. 7, pp. 4257-4266, 2015.

[28] C. Pukdeboon, A. S. I. Zinober, and M.-W. L. Thein, "Quasi-continuous higher order sliding-mode controllers for spacecraft-attitude-tracking maneuvers," IEEE Transactions on Industrial Electronics, vol. 57, no. 4, pp. 1436-1444, 2010.

[29] Y. Feng, X. H. Yu, and F. L. Han, "High-order terminal slidingmode observer for parameter estimation of a permanentmagnet synchronous motor," IEEE Transactions on Industrial Electronics, vol. 60, no. 10, pp. 4272-4280, 2013.

[30] X. Yu and M. Zhihong, "Fast terminal sliding-mode control design for nonlinear dynamical systems," IEEE Transactions on Circuits and Systems I: Fundamental Theory and Applications, vol. 49, no. 2, pp. 261-264, 2002.

[31] L. Yang and J. Yang, "Nonsingular fast terminal sliding-mode control for nonlinear dynamical systems," International Journal of Robust and Nonlinear Control, vol. 21, no. 16, pp. 1865-1879, 2011. 


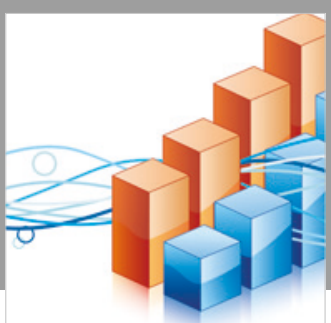

Advances in

Operations Research

\section{-n-m}
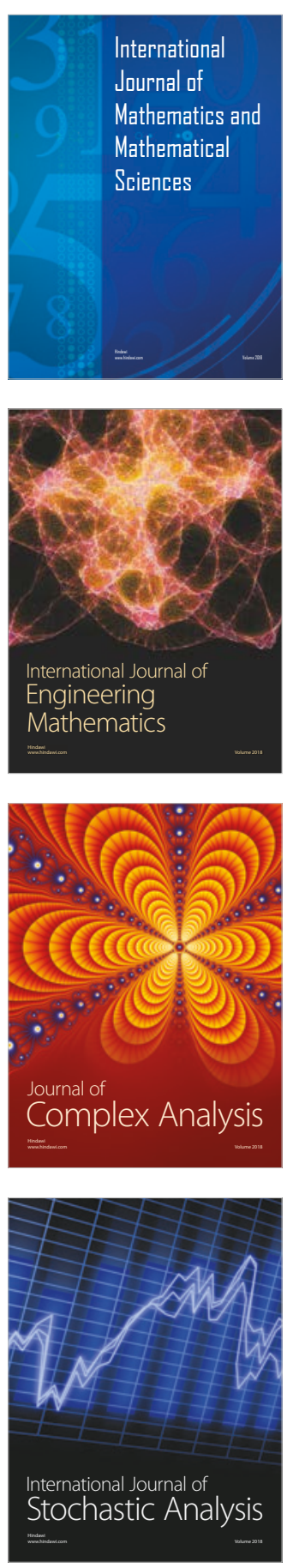
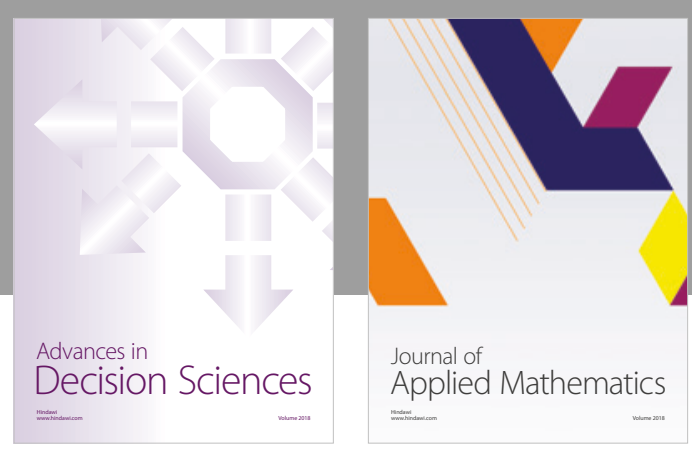

Journal of

Applied Mathematics
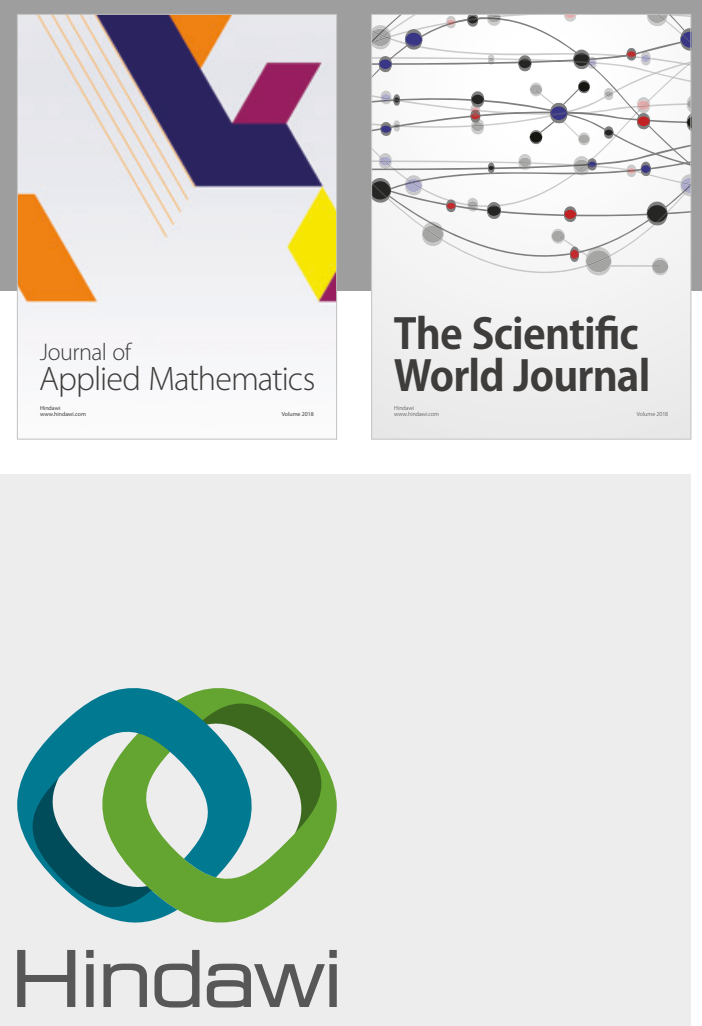

Submit your manuscripts at

www.hindawi.com

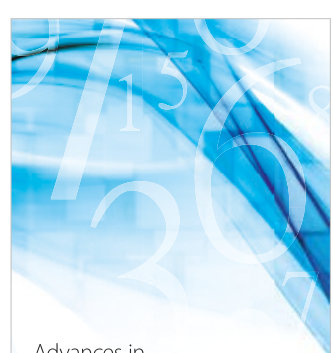

Advances in
Numerical Analysis
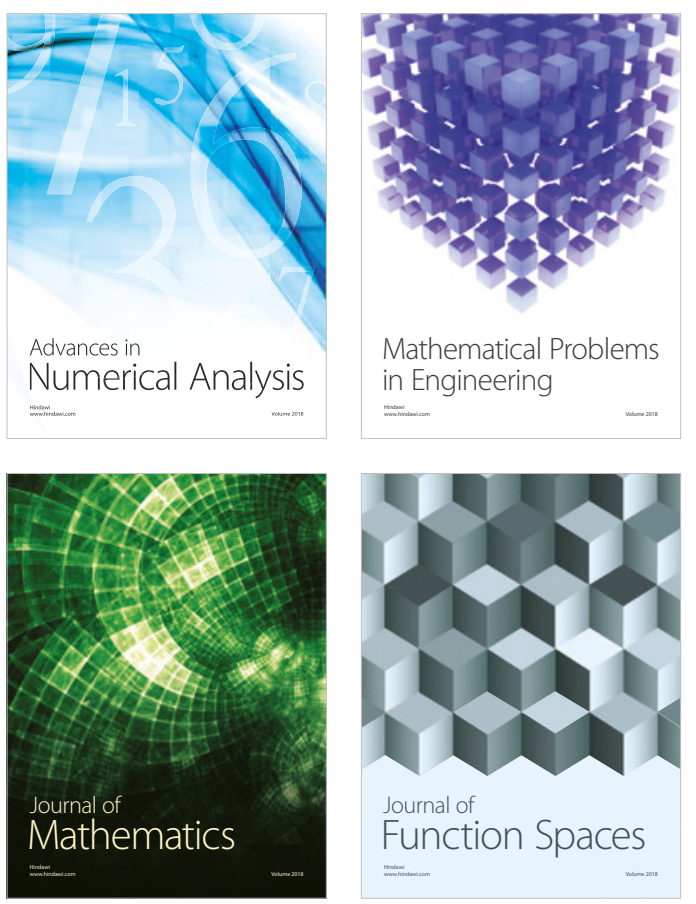

Mathematical Problems in Engineering

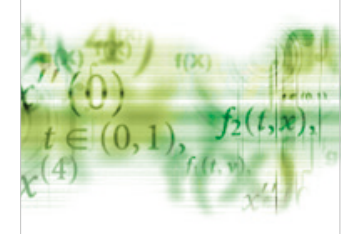

International Journal of

Differential Equations

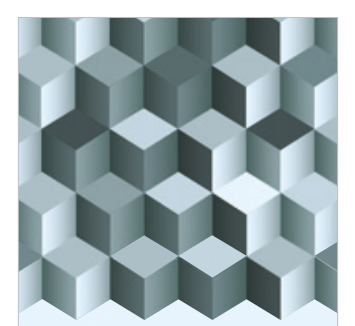

Journal of

Function Spaces

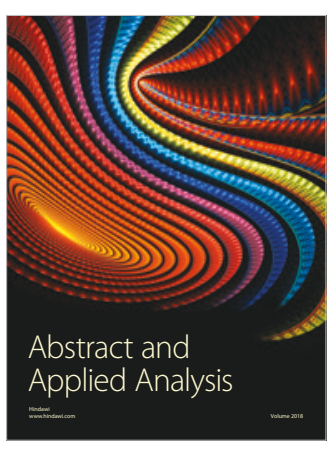

The Scientific

World Journal

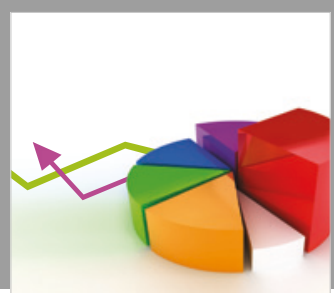

Journal of

Probability and Statistics
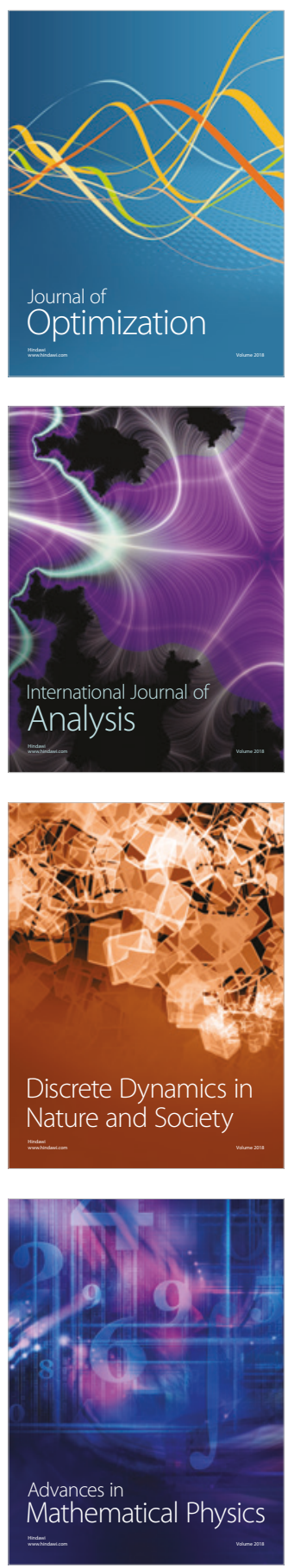